

DOCUMENTO CEDE 2004-28

ISSN 1657-7191 (Edición Electrónica)

AGOSTO DE 2004

\title{
CEDE
}

\section{THE ECONOMICS OF TRANSMILENIO, A MASS TRANSIT SYSTEM FOR BOGOTÁ*}

\author{
JUAN CARLOS ECHEVERRY ${ }^{\star \star}$ ANA MARÍA IBÁÑEZ ${ }^{* \star \star}$ \\ AND LUIS CARLOS HILLÓN ${ }^{* \star \star}$
}

\begin{abstract}
By the end of the 1990s, inefficiency, excess supply and low service quality characterized the mass transit system of Bogotá. The average travel time to work was one hour and ten minutes, obsolete buses provided public transport, traffic generated 70 percent of air pollution and there were frequent traffic accidents. To address all of these issues, the municipal and national governments designed and put in place a new mass transit system named TransMilenio (TM), which came into operation in January 2001. The purpose of this paper is to analyze Bogotá's mass transit system before and after TM, study the political economy of its adoption process and conduct a cost-benefit analysis (CBA) of the first phase of the system. The new transit system is a hybrid model that combines public planning of the network structure, route tendering conditions, regulation and supervision, as well as private operation of the separated functions of revenue collection and transport service. The adoption of this new model needed to resolve delicate political economy issues that characterized private transport systems in many developing countries. The new organization had a sizeable impact on TM users' by improving traveling conditions significantly. In addition, congestion, pollution and traffic accidents plummeted in TM corridors. However, the type of transition adopted for the remaining transport corridors not covered by TM caused unforeseen negative spillovers, as a consequence of slow scrapping rates and bus and routes relocation. Consequently, although the CBA for the first phase of the corridors covered by TM is positive, once these additional measures are taken into consideration, the net effect is negative due primarily to increases in travel time for passengers using the traditional transport system. In order to minimize the negative spillovers during the full implementation of TM, expected to last until 2015, integration of the traditional and new systems should be carried on, and strict regulation of the traditional public transport system should be crafted.
\end{abstract}

Key words: urban transport, political economy, cost-benefit analysis

JEL classification: R41, D78, D61

\footnotetext{
* We express our gratitude to Marcela Meléndez and Edgar Sandoval who worked on a first draft of this paper. We are particularly grateful to Andrés Gómez-Lobo for the on-going cooperation with successive drafts as well as to Mauricio Cárdenas, Norman Offstein, Andrés Velasco and participants to the Economia seminar in Cambridge, Mass., and to Seminario CEDE in Universidad de los Andes, Bogotá. Excellent research assistance was provided by Andrés Moya, Ángela Fonseca and Mónica Hernández.

${ }_{* * *}^{*}$ Department of Economics, Universidad de los Andes, Bogotá, Colombia. jechever@uniandes.edu.co

${ }^{* * *}$ Department of Economics, Universidad de los Andes, Bogotá, Colombia, aibanez@uniandes.edu.co

${ }^{* * * *}$ Ministry of the Environment, Bogotá, Colombia. Ichillon@cable.net.co
} 


\title{
ANÁLISIS ECONÓMICO DE TRANSMILENIO, EL SISTEMA DE TRANSPORTE PÚBLICO DE BOGOTÁ
}

\begin{abstract}
Resumen
A finales de la década de los 90 el sistema de transporte masivo en Bogotá estaba caracterizado por ineficiencias, exceso de oferta y una baja calidad en el servicio. El tiempo de viaje promedio era de una hora y diez minutos, el servicio era proporcionado por buses obsoletos, el tráfico vehicular generaba el 70 por ciento de la polución y los accidentes de tránsito eran frecuentes. Para solucionar todos estos problemas, los gobiernos distrital y nacional diseñaron e implementaron un nuevo sistema de transporte masivo llamado TransMilenio (TM), el cual inició operaciones en Enero de 2001. El propósito de este artículo es examinar el sistema de transporte masivo en Bogotá antes y después de la implementación de TM, analizar la economía política del proceso de adopción y transición y llevar a cabo un análisis costobeneficio (CBA) de la primera fase del sistema. El nuevo sistema de tránsito es un modelo híbrido que combina la planeación pública de la infraestructura, asignación de las rutas, regulación y coordinación así como la operación privada de las diferentes funciones de recolección de ingresos y servicios de transporte. La adopción e implementación de este nuevo sistema debía resolver delicados problemas de economía política que caracterizan a los sistemas privados de transporte en muchos países en desarrollo. La nueva organización del sistema de transporte masivo tuvo un impacto considerable sobre los usuarios de TM, al mejorar significativamente las condiciones del servicio y reducir la congestión, polución y los accidentes de tránsito en los corredores de TM. Sin embargo, el tipo de transición que se adoptó generó externalidades negativas sobre los otros corredores de la ciudad debido a las bajas tasas de chatarrización y a la consecuente reubicación de rutas y buses. Por lo tanto, aunque el CBA para los corredores de TM arroja resultados positivos, una vez se toman en consideración las externalidades sobre los otros corredores, el efecto neto es negativo principalmente debido al aumento en el tiempo de viaje para los usuarios del sistema tradicional. Para minimizar estas externalidades negativas, durante la implementación completa de TM que irá hasta el 2015, se deben integrar los dos sistemas y adoptar una estricta regulación sobre el sistema tradicional de transporte público.
\end{abstract}

Palabras clave: transporte urbano, economía política, análisis costo-beneficio

Clasificación JEL: R41, D78, D61 


\section{Introduction}

During the nineties, mass transit in Bogotá was characterized by inefficiency, excess supply and low quality service. The average travel time to work was one hour ten minutes, obsolete buses provided public transport, average speed could reach ten $\mathrm{km} /$ hour during peak hours, 70 percent of air pollution was generated by traffic, and traffic accidents were frequent. City transport was in the hands of private entrepreneurs and local authorities were in charge of regulating the system and the provision and maintenance of the road infrastructure. By the end of the decade, a new mass transit system, named TransMilenio (TM), was designed and partially implemented to solve these large inefficiencies of mass transit in Bogotá.

TransMilenio significantly improved traveling conditions for its users and reduced traffic externalities on served corridors. The system reduced travel times for TM users by 32 percent, particulate matter pollution fell by nine percent in some areas of the city and accident rates dropped by 90 percent in the TM corridors. By 2015, the complete TM system is expected to transport 80 percent of the city's population at an average speed of $25 \mathrm{~km} / \mathrm{h}$ with a service quality similar to an underground metro system.

These achievements result from a careful, hybrid scheme designed to overcome many market failures that plague the provision of mass transit in developing countries. The public participation in the network configuration, the route tendering conditions and the system regulation and supervision, is accompanied by the private operation of buses; the vertical separation among the transportation service and the fare collection process broke the link between passenger-trips serviced and profits; the allocation of exclusive property rights over a route and a competitive tendering process to give the right to operate on a route, are among the most salient features on the design of TM.

The purpose of this paper is to examine the process leading to the implementation of TM and evaluate the impact of the first phase of the new system. We explore three issues. First, we analyze the market failures prevalent in the provision of public transport. Second, we describe the mass transit system in Bogotá before and after TM and study the political economy of the process. Lastly, we examine the impact of TM on the quality 
of life of inhabitants in Bogotá and conduct a cost-benefit analysis of the first phase of TM.

The results of this paper show that three factors contributed to the smooth transition from the existing mass transit system in Bogotá to the adoption of TM. First, the excess supply of buses exerted, by the end of the nineties, a costly toll upon the public transport system: economic rents declined and never recuperated the high peak reached at the end of the eighties. Second, the Local Government convinced traditional firms to support TM by allowing them to join the new system as operators and to continue supplying services in unserved TM corridors. Thus, traditional firms derived benefits from participating in TM and in the traditional system. Moreover, the structure of the traditional system was not modified; regulation was still weak and fares provided incentives to the entry of new buses. Third, the scrapping of buses was slow, promoting the relocation of these vehicles to unserved TM corridors, which reduced the losses to the politically powerful group of traditional transporters from adopting TM. However, the relocation of buses produced negative spillovers to unserved corridors; thus, congestion, pollution and travel times for riders of the traditional system worsened. Despite the sizeable impact TM had on its users, the net benefits of implementing the first phase are negative as a result of the spillovers caused by the slow scrapping rates and the maintenance of a weak regulation of the traditional system. A similar system is now being implemented on other smaller cities around Colombia with weaker political and regulatory commitment from municipal authorities.

The paper provides important policy lessons for cities planning to undertake similar reforms in the sector in developing countries. On the one hand, political hurdles could dampen the reform of the sector. The paper contributes to understand the political economy process by which the local and national authorities involved the private entrepreneurs, previously operating the deficient mass transit system, in the development of a new scheme. On the other hand, the cost-benefit analysis identifies policy mistakes during the implementation of TM that lead to negative spillovers, reducing the benefits of $\mathrm{TM}$. Recognizing upfront these risks is useful to avoid similar mistakes in cities that are planning to reform their mass transit system. 
The paper is organized as follows. Section 2 revises the market failures prevailing in the provision of public transport. Section 3 describes the mass transit system of Bogotá before TM, illustrates the main characteristics of the new system, and discusses the political economy in its design and implementation. Changes in the quality of life, positive or negative, resulting from the new mass transit system as well as of its particular adoption and the cost-benefit analysis are included in Section 4. Concluding remarks are presented in Section 5.

\section{Market failures in urban bus services in developing countries ${ }^{1}$}

Many cities in developing countries have experienced a pendulum in the operation of their public transit system. Bogotá, for instance, evolved from originally privately owned trolley buses at the end of the ninetieth century to a fully public bus system in the first half of the twentieth. The second half of last century witnessed a slow transition back to private ownership due to the lack of flexibility and productive inefficiencies that became characteristic features of state ownership and operation. The mixed success of the last decades with regard of private provision, liberalization and competition in the market especially in the cities of developing countries led to a reconsideration of this model, and the adoption of so-called hybrid models that combine public and private features. The main reason for this paradigm shift is the evidence of market failures that hinder a fully private provision to reach socially optimal outcomes.

Market failures in the provision of urban mass transit include: unclear definition of property rights on the curbside and on the road; fares set above the competitive equilibrium levels; misalignment between the incentives of bus drivers and owners; and finally, congestion and pollution. In developing countries, these market failures are exacerbated by weak regulation and enforcement.

Property rights are usually not clearly defined on the road or on the curbside (Klein et al, 1997). The absence of properly defined "rights to waiting passengers" implies that the fare from a pedestrian at the curb does not belong exclusively to the firm authorized to

\footnotetext{
${ }^{1}$ This section draws upon Estache and Gómez-Lobo (2004).
} 
operate on that route. Taking advantage of the lack of regulation and control and of the fact that waiting time is costly ${ }^{2}$, other means of transportation can interlope and offer the pedestrian a ride.

However, the implication of this lack of property rights differs in developed and developing countries. Since demand for mass transit in developed countries is low and is induced by a regular high quality service, investments on mass transit may not be recuperated given that any competitor can take away passengers. This induces underinvestment. On the other hand, demand in developing countries is "thick" ${ }^{3}$, fares are high, and excessive bus entry is the norm, resulting in strong competition for passengers on the curb. This strong competition spurs distortions in investment such as deficient quality service and the use of small vehicles, which are more maneuverable, but produce more pollution, congestion, large investment per seat, and safety problems (Estache and Gómez-Lobo, 2004).

Fares are usually set above the competitive equilibrium levels, which may also promote an excessive number of buses. Because buses are not perfect substitutes, price competition is not an effective mechanism to regulate the optimal quantity of buses in the market. To minimize waiting time, riders prefer to use the first bus that arrives even though in a few minutes a cheaper bus may come along. Time, and not fares, is the most important decision variable for the rider; therefore, the bus can exercise its "market power" by raising fares. As a result, they are above efficient levels and returns to investment are high, creating incentives for the entry and an excessive number of buses on the road (Evans, 1987). This excessive supply of buses paired with a deficient quality service lead to congestion, pollution, and traffic accidents.

A second source of market failures is the misalignment between the interests of the bus driver and the bus owner, introducing further inefficiencies in the provision of mass transit. The profits of bus owners depend on the number of passengers carried per bus. In order to align the interests of bus owners and drivers, the payment of bus drivers is typically based on the number of passengers carried. This contract between the owner

\footnotetext{
2 There is evidence that passengers consider waiting time more costly than travel time.

${ }^{3}$ In fact, most of the population in these countries lacks other alternatives of transportation.
} 
and the driver introduces however further complications on the provision of mass transit. On the one hand, bus drivers compete for passengers to maximize their payments, causing safety problems and congestion. On the other, this compensation scheme promotes the use of smaller buses, despite the congestion and pollution problems, because they are better equipped to compete for passengers (Estache y Gómez Lobo, 2004).

When drivers are responsible for fare collection, the problems described above are deepened and new inefficiencies arise. The high costs of monitoring the driver cause the atomization of the bus industry in terms of bus ownership, in order to bring closer the interests of bus owners and drivers. Although this atomization is effective to align the interest of the owner and drivers, additional costs emerge. The large number of owners makes it difficult to exploit economies of scale on coordination as well as economies of density.

The aforementioned market failures are worsened by deficient regulation, weak enforcement and capture of institutions. The next section examines the evolution of mass transit in Bogotá using the framework described in this section and emphasizing as well on policy failures that were present in the city.

\section{TransMilenio's background, features and adoption process}

The mass transit system of Bogotá before 2001 was characterized by an oversupply of vehicles operating at a level where inefficiencies in production and negative congestion externalities were present. How this situation emerged and was maintained throughout decades, and how a completely new system as TM was enacted against powerful vested interests, with a relatively low political turmoil in a surprisingly short $\operatorname{span}^{4}$, are questions that demand an exploration of the political economy of the transition process. The purpose of this section is to examine the mass transit system before TM, the solution implemented, and the political economy process associated with its adoption.

\footnotetext{
${ }^{4}$ It took less than three years from the moment in which the original decision was made and the inauguration of the first line of TM.
} 
The Mass Transit System before TM

The structure that characterized the public transportation system of Bogotá in the second half of the twentieth century until the implementation of TM can be divided into three periods: (i) simultaneous provision by state and privately owned buses (until the mid-1980s); (ii) privately owned buses and affiliation firms with weak quality discrimination (until the early 1990s); and (iii) private provision with strong quality discrimination (from the early 1990s to the present). This type of evolution was not exclusive to Bogotá, but shared with many other cities of developing countries.

During an initial phase of the period 1940 - mid 1980s, mass transit was exclusively provided by a public company; resulting in inefficiencies, excess drivers per vehicle and inflexibility in supplying sufficient transport services and new routes for a growing city (Urrutia et al., 1981). Increasingly, the regulatory agency solved the insufficient supply of buses and routes by allowing for participation of private firms in the provision of public transport, the decisions related to new routes and the determination of the number of vehicles running on each corridor.

The new scheme, allowing for participation of private owners, had three types of actors: the local government, bus owners, and firms acting as intermediaries between them. The local government granted stable routes and fare subsidies to private firms. To the bus owner, authorization to operate on a certain route (i.e. affiliation) involved the purchase of one of the fixed number of slots approved by the authority, and the payment of an affiliation and a monthly fee ${ }^{5}$ to the affiliating firm. Affiliating firms were not necessarily proper transportation companies but could act only as intermediaries with the role of gaining governmental approval (licenses) for routes and affiliating vehicles to guarantee a level of service. No contract between the government and the firms existed.

At the beginning of the 1980s, the fare subsidy system, which constituted a sufficient return for the investment, became the main factor in determining the number of buses in service; however, it created incentives to purchase buses and use them for six hours,

\footnotetext{
${ }^{5}$ In 1995 , the cost per slot was between US\$2,300 and US\$4,600, the affiliation fee ranged between US $\$ 100$ and US $\$ 600$ and the monthly fee varied between US\$35 and US\$5 (Lleras, 2003).
} 
the span necessary to receive the subsidy. Typically, drivers utilized more than one vehicle during their daily shift in order to collect the government subsidy.

During the eighties, the gradual elimination of subsidies led to two types of developments. First, higher fares were granted to non-subsidy vehicles, obliged to comply with better quality conditions. This was the first experience of price discrimination based on quality, a tool that would become important at the beginning of the 1990s. Second, the industry intensified its organizational structure, separating even more the affiliating firms, the bus owners and the drivers. Bogotá did not liberalize fares at any point in time, as it was the case in Santiago de Chile (Estache and Gomez-Lobo, 2004), but let them to be set by the regulator agency, allegedly subject to capture by the priv7ate operators and prone to accept high fares.

The atomization of the ownership structure was caused by the high costs of monitoring the revenue collection of each bus, responsibility of each driver. This solution of the agency problem mentioned above led the affiliating firms to specialize in obtaining routes from the authorities and affiliating as many buses as possible. Since aging of the existing fleet increased the cost of owning old vehicles, the firms sold them, usually to the drivers themselves, and owned only new buses ${ }^{6}$. At this point the number of vehicles on the streets was completely determined by the affiliating firms, because the public company had been liquidated. The firms obtained as many routes and buses as possible because they earned more revenues from affiliation than from the number of passengers transported in their own buses, restricted to ten percent of the fleet. The firms also established a cartel to consistently push for higher bus fares ${ }^{7}$ and the authorization of longer bus usage lives as well as to avoid price competition. This structure intensified their struggle for economic rents, led to an increase in the number of buses in the streets, and allowed for aging of the vehicle fleet.

\footnotetext{
${ }^{6}$ The increase of drivers-owners as a solution of the limited monitoring capacity of the affiliating firms is also documented by Estache and Gomez-Lobo (2004) for the case of Santiago de Chile.

${ }^{7}$ Bus fares were historically agreed upon through costly negotiation processes with the local authorities. Only in 1997 an effort was put forth to tie them to a transport good basket (Decree 3109 of 1997).
} 
As Figure 1 illustrates, the bus fleet of public transit vehicles in Bogotá grew steadily during the last three decades. Because fares were constantly adjusted upwards, revenues per passenger increased permanently, providing incentives for entry.

Figure 1. Total public transit vehicle fleet in Bogotá, 1970-2003

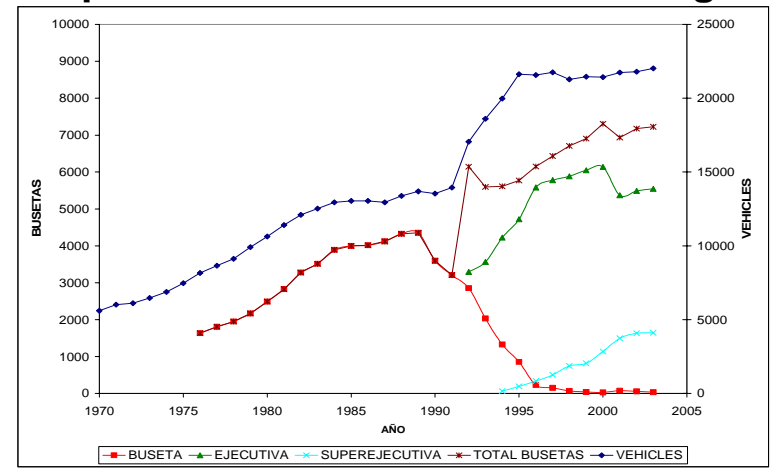

Source: Authors calculations based on DANE

Estache and Gomez-Lobo (2004) propose a model for explaining the over provision of services in a private equilibrium when fares are too high. The key argument is the fact that buses are not perfect substitutes, but differentiated products. Hence, the bus stopping in front of a passenger enjoys a "market power" over its competitors due to the cost-of-waiting, highly valued by eventual passengers; this permits it charging a higher fare. Consequently, rising tariffs create excessive returns to investment and promote the entry of new buses beyond the socially efficient level (see p. 12-15). As a result of excessive entry, buses in Bogotá and Santiago de Chile have witnessed a sharp decline in occupancy, as it will be illustrated below.

In the case of Bogotá, the steady average fare increase also stemmed from the strong lobbying capacity of the public transport sector and the quality discrimination strategy adopted by private firms ${ }^{8}$. As Figure 2 illustrates, from 1975 to 2004, the average fare increased from US\$0.10 to US $\$ 0.40$, in constant 1999 dollars. Since Bogotá did not

\footnotetext{
${ }^{8}$ The quality discrimination strategy implemented by private firms was successful since the fares for busetas and colectivos, small sized-vehicles with faster service, were set 2.5 times higher in contrast to the normal bus fare.
} 
experiment with fare liberalization, these fare increments were mostly the result of a strong bargaining power of private transport firms attained during the $1980 \mathrm{~s}^{9}$.

Figure 2. Bus fare and average occupancy, 1970-2003



Source: Authors calculations based on DANE

The declining trend in average occupancy remained through the rest of the decade: the daily number of passengers per vehicle, fell dramatically from 538 in 1992 to 294 in 2003. The constant fare hikes offset the subsequent income losses, and served as an incentive for the entry of more vehicles and further reductions in the number of passengers per vehicle.

The economic rents, determined by high fares, provided incentives for the entry of new vehicles and delayed the exit of old ones. In order to estimate the rents for Bogotá's mass transit system, the contracts between affiliating firms and owners/drivers were simulated (see Annex I). Figure 3. presents the results and shows that the sector operated at efficiency levels during two periods: the end of the 1970s and the beginning of the 1990s. Besides these two periods, economic rents were positive and substantial, and varied sharply. In particular, during the eighties rents grew along with fare increments from US $\$ 0.10$ to US $\$ 0.30$, a change associated with the introduction of smaller capacity vehicles. Interestingly, rents accrued to both the fleet administrating firms and the bus owners/drivers.

\footnotetext{
${ }^{9}$ Private transporters started to participate in politics either directly via their own candidates in the city council or indirectly via funding the campaign of traditional politicians.
} 
However, the composition of rents changed during the nineties. Rents accrued mainly from affiliation, and rents for bus owners/drivers were small and contingent upon the number of passengers. Consequently, rent distribution shifted and favored the affiliating firms, as Figure 3. shows. The figure also reveals that during the nineties the total daily rents never returned to the peak observed at the end of the eighties.

Figure 3. Daily simulated economic rent per vehicle

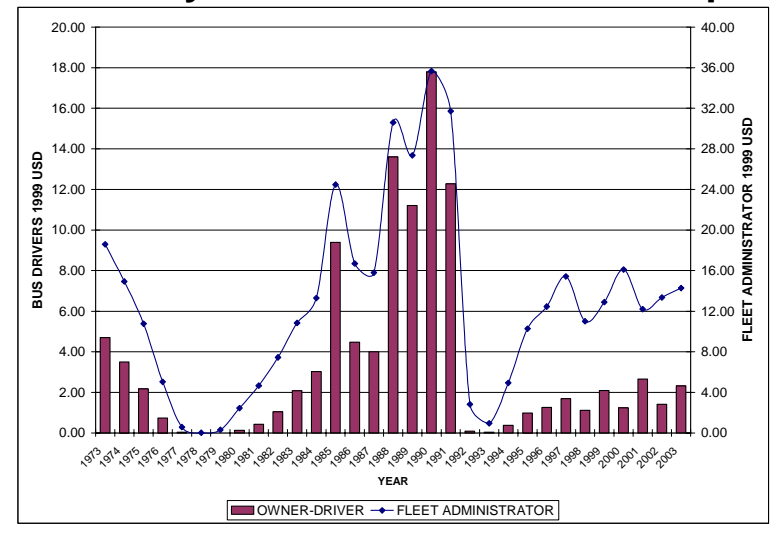

Source: Authors calculations based on DANE

At the beginning of the nineties, the affiliation firms lobbied for further price discrimination based on quality. The so-called "executive" services, with only sitting passengers, newer vehicles and faster service started to compete in the streets at higher fares. Again, the three types of actors involved, firms, owners and drivers, obtained benefits at the expense of passengers, due to the acceptance by the authorities of this new price setting mechanism. It has been widely argued that this behavior reveals either the capture of the regulator or ignorance regarding the true costs of bus transportation, or both.

As a consequence, a market failure due to the absence of price competition in urban bus transport was exacerbated by a policy failure that granted free affiliating privileges to these firms and periodic fare negotiation with a cartel, leading to systematic economic rents. In addition, this incentive scheme forced bus drivers to engage in a strong competition for passengers along the central corridors. Drivers did not respect assigned 
bus stops or delineated areas for bus transit in the pursuit of passengers and, in the extreme, did not respect route-assignment at all ${ }^{10}$.

At the end of the 1990s the excess bus supply, coupled with a substantial increase of private vehicles, exceeded the traffic capacity of Bogotá. From 1991 to 1995, the number of cars registered in Bogotá increased by 75 percent and 40 percent of the country's vehicles were circulating in the city (Lozano, 2003). By 1998, private cars occupied 64 percent of the road space and mobilized only 19 percent of the population (Chaparro, 2002). Moreover, the public transportation fleet doubled during the period 1980-1999 reaching a total of 22,031 buses (Lleras, 2003).

As a result, gridlock was commonplace, accidents abounded and travel times were unbelievably high. Estimates show that in 1995 the average number of daily trips per household was 11.9, the average number of daily trips per person was 1.7 and the total number of daily trips surpassed 10 million $^{11}$. The average speed for public transportation vehicles was ten kilometers per hour and in peak hours average speed could drop to five $\mathrm{km} /$ hour (Chaparro, 2002). Inequality of travel times between public transport users and car owners was sizeable. Mean travel time was 66.8 minutes for public transport users whereas car owners faced a mean travel time of 42.6 minutes (Lleras, 2003). These problems finally led to a rethinking of the entire bus transport system in Bogotá and to the design and partial implementation of the TM system by 2001.

\section{The features of TransMilenio}

The form of intervention adopted with TM had precedents. During the 1980s the authorities created exclusive bus lanes along the most important south-north corridor in the city, while leaving the structure of the public transport system described above intact; Curitiba-type reforms were already proposed; and finally, under the leadership of the National Government, a metro system was under consideration. Thus, there was a real possibility of comprehensive intervention to reform the existing system.

\footnotetext{
${ }^{10}$ The road infighting among drivers for every extra passenger is locally known as "the penny war" ( $L a$ guerra del centavo).

${ }^{11}$ During 2000, Hong Kong, with a population similar to Bogotá (7'394.170 inhabitants), reported 12 million total daily trips.
} 
The elements of the new system that lie at the center of the transformation and seem worth looking at more slowly are: (i) the Bus Rapid Transit system; (ii) the concession contracts for service providers (TM transporters and feeder buses); (iii) the vertical separation among the transportation service and the fare collection process; and (iv) the new price setting procedures.

TransMilenio is "a flexible, rubber-tired rapid transit mode that combines stations, vehicles, services, and driving lanes, ...into an integrated system." (Lleras, 2003). Designed for 35.000 passengers per hour per direction, the first phase of TM covers 42.4 kilometers of exclusive bus lanes along three of the main transit corridors (see Map 1). In these corridors, central lanes are exclusively set for the operation of TM, and passengers at the stations are their exclusive customers. The stations are located in the middle of the road facilitating the transfer between buses, mimicking the metro system. The bus stops are 57 stations, located every 700 meters, and are equipped with pay booths, registering machines, surveillance cameras, and infrastructure such as bridges, pedestrian crossings and traffic lights designed to ease the entrance of passengers into the system. At the end of the corridors, three principal access stations were built as the meeting point for the feeder buses, and buses from the traditional system that work in the neighboring municipalities. Feeder bus passengers have an integrated tariff so riders do not have to pay twice for using the feeder system and TM.

Map 1. First lines of TransMilenio: Ave. Caracas-Autop. Norte and Ave. 80

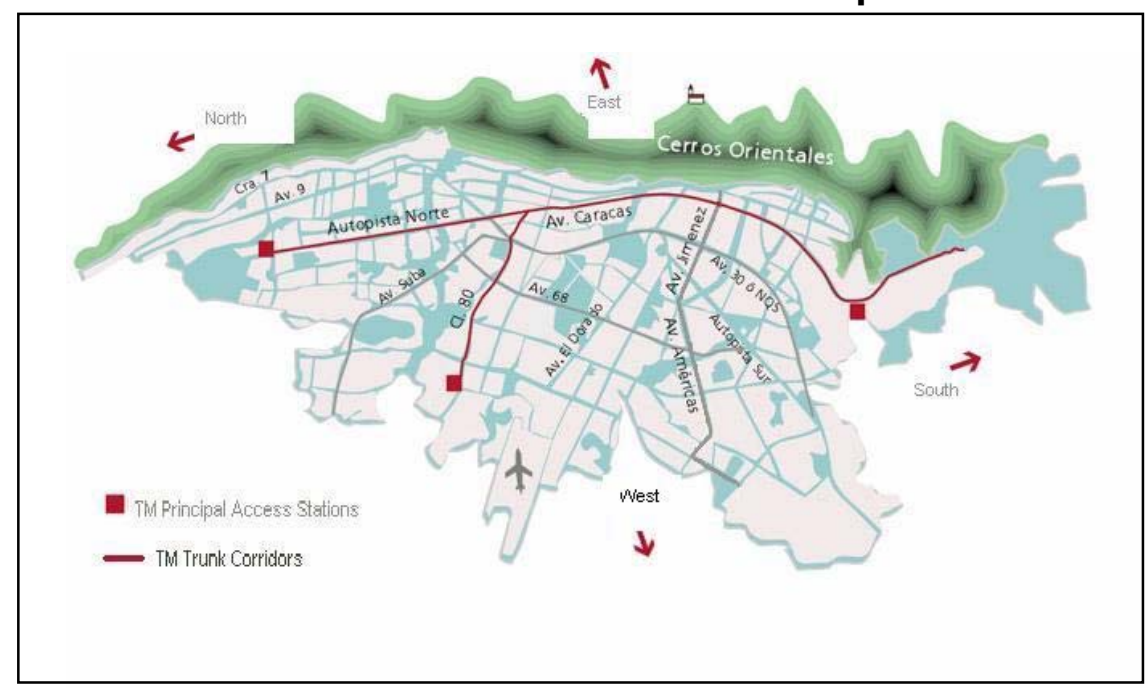

Source: Transmileno S.A. 
The bus fleet for the first phase of the system is constituted by 470 buses, characterized by having superior mechanic conditions and environmental performance than those of the Traditional System. Feeder buses, sharing corridors with the traditional system, have bus stops every 300 meters in the lower socioeconomic areas of the city and are synchronized by the operators with a satellite system in order to minimize traveling and waiting times for passengers. ${ }^{12}$

Finally, TM designed a pre payment scheme, where users buy tickets in paying booths located in the stations, just as in underground systems around the world. Therefore, bus drivers do not have to deal with collecting payment fares as happens in buses operating in the traditional system. The organizational scheme of service delivery through exclusive bus transit lanes and closed stations implies a clear definition of property rights on the road and curbside.

Under the TM system the transportation service is organized through concession contracts awarded by public competition. Transport providers, both local and foreign, are called to associate and participate under a new set of rules. The new transport firms are to own a number of buses that meet certain specifications, whose operation is subject to the leadership of a central authority, TransMilenio S.A.. These buses have a specified usage life stipulated at the outset of the contracts. The concessions expire when the vehicle fleet reaches an average mileage of 850,000 kilometers, with no bus individually reaching more than $1,000,000$ kilometers. If the average mileage threshold is reached prior to ten years, then the concession extends to the 10th year. If, on the contrary, the average mileage threshold has not been reached by year 10 , the concession lasts until this happens or until year 15 , whichever comes first ${ }^{13}$.

In addition, the income of the concessionaries is no longer associated to the number of passenger-trips serviced. The new contracts establish a per kilometer traveled payment. The number of kilometers traveled depends on the manner in which the central authority dispatches service and, ultimately, on demand. In fact, reward per kilometer traveled is

\footnotetext{
${ }^{12}$ Each TM bus has a capacity of transporting 160 passengers while Feeder buses can transport 70 passengers.

${ }^{13}$ There is a restriction by which the concessionaire is forbidden to add new vehicles to the fleet to deliberately bring its average mileage down when a certain portion of the concession period has expired. This contract resembles those analyzed by Engel et al (2001).
} 
the central variable by which the firms compete for these contracts. TransMilenio S.A. has thorough calculations of the costs involved in the provision of the transportation service, as well as demand forecasts, allowing it to set the range of acceptable fees per kilometer traveled. This range is set to guarantee a "fair" return to the participating investors ${ }^{14}$ and is used as a parameter in the selection process of the concessionaries. In this way, TM creates a hybrid-model that replaces competition on the road by competition for the road (Estache and Gomez-Lobo, 2004).

With these measures, the entire incentive scheme of the previous system is turned upside down. The affiliating firm and the license business disappear, and the ability to gain from cutting maintenance costs also disappears since the service is to be provided during a specified time period under some safety and efficiency standards; cutting down on costs today will imply incurring greater costs tomorrow in order to comply. The firm comes into existence as a true transport firm able to earn a return on its capital comparable to what it would receive in any other business of comparable risk.

Feeder buses are also organized through concession contracts awarded by competition. The contracts here are slightly different: they are awarded for a 10-year period subject to the condition that no individual vehicle should reach more than 950,000 kilometers during the time of the concession, and income to the feeder buses is defined as a combination of revenues from a payment per kilometer traveled and a payment per passenger served. The reward system is designed to prevent opportunistic behavior from the transport firms. Feeder buses bring passengers from outskirt locations into the TM system, but most of the time they do not transit on exclusive public transport lanes, making it impossible to control for the kilometers they travel. The regulating authority, TransMilenio S.A., has calculated the maximum fixed operation costs that a firm will incur per bus and agrees to pay a per kilometer traveled fee. Under this rule traveling without passengers becomes unprofitable for the feeder bus.

${ }^{14}$ This range is given by a real return on investment between $14 \%$ and $16 \%$. 
Taking the responsibility of collecting fares away from the bus drivers ${ }^{15}$ and centralizing the management of fare revenues under an independent fiduciary entity is another element that contributes to the improved operation of the new system. Booths at the TM stations collect revenues of the system, and they are managed through a fiduciary contract. This not only relieves the system of information asymmetries and aids in the collection of taxes, it also has a considerable impact on road safety. ${ }^{16}$

The last important element of the new scheme is the fare setting procedure. Under TM, travel fares cease to be negotiable. The contracts written subject the concessionaires to operate under the fares set by the regulating authority, TransMilenio S.A.. The fare setting procedure and fare adjustment over time form part of the contracts. TM travel fares are set to cover the long-run average costs of operation, including the administration costs of the regulating authority and costs of the fiduciary contract through which fare revenues are managed.

An upfront decision made during the design stage of TM was that fares would not be set to recover the infrastructure investments since that would render the system not feasible. TM fares set to recover the operation costs of the system were already significantly higher than the current bus fares. Investment in the infrastructure required to operate the system was said to be social investment, and TM's infrastructure thereafter became "social infrastructure."

After the introduction of the first lines of TM, buses from the traditional system continue to mobilize nearly 80 percent of the population, with approximately six million passengers a day. Despite the concession contracts for TM obliged the operators to purchase and scrap buses that previously operated in TM corridors, only 1,410 buses were effectively scrapped and the remaining 6,000 buses were relocated into unserved TM corridors. Although the demand for the old system dropped, and consequently revenues per vehicle fell, a loose regulation of the system permitted and favored the excessive entry and the over provision of services in these corridors. Moreover, once TM came into operation the fares for the traditional system were tied to the TM fares,

\footnotetext{
${ }^{15}$ In the previous system, passengers paid the drivers upon entering the buses, a distraction to the drivers that contributed to congestion and accidents.

${ }^{16}$ At the moment, regulator lacks a direct monitoring instrument for the fare collection contract.
} 
and, as illustrated in Figure 4. Consequently the introduction of TM did not spur a substantial reduction in the transport fleet of buses from the traditional system.

Figure 4. Fares: Buses versus TM

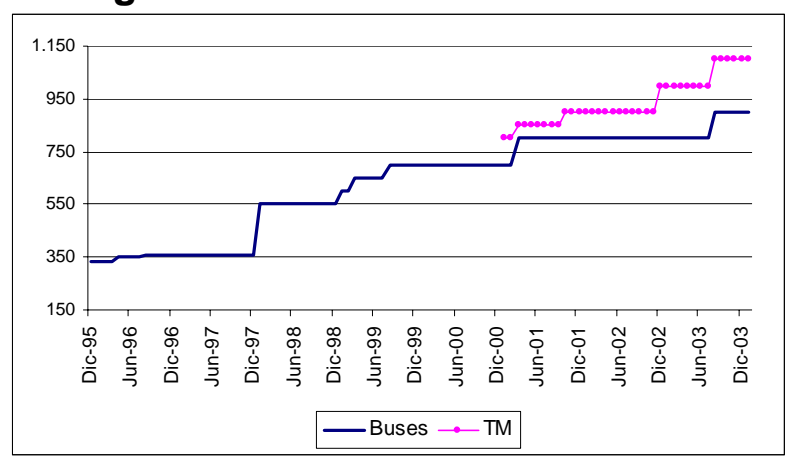

Source: TransMilenio S.A.

\section{The political economy of TransMilenio's adoption}

Against all odds, the political struggles associated with TM's adoption were surprisingly minor. The traditional firms had derived substantial, although fluctuating rents over the decades and understood the political leverage necessary to effectively determine bus fares. However, with the possibility of having to face a completely new system, these actors considered that they had plenty to loose. Negotiations between the local government and representatives of the traditional transport system went on for more than one year. Convincing them that there were ripe gains from adopting the new system, both for the city as a whole and for transport business in particular, demanded a comprehensive strategy.

The crucial issues of the strategy leading to the alignment of traditional bus owners with the local government were, first, the fact that at the end of the 1990s public transportrelated problems like congestion, pollution and accidents reached worrying levels. Second, they had also already experienced policy changes that affected them and which they were not able to counter, like the abolition of subsidies and the levying of a gasoline tax. Therefore, at the end of the 1990s they faced a growing consensus in favor of a regime change, either in the form of a subway or a transformation of the bus system. 
As Estache and Gomez-Lobo (2004) document for the case of Santiago de Chile, where strikes against the reform to the liberalized regime allowed for extractions of considerable rents, in Bogotá there were also several episodes of protest. It is interesting though that the strikes and protests lost momentum quite rapidly and TMrelated ones were outnumbered by other issues. Table 1 shows that between 1999 and 2000 there were five events against TM; at the same time other issues produced greater concern than the new system. Indeed, even at the peak of TM related protests, they represented only one fifth of the total political demonstrations in the sector. By 2001 activity against this initiative had already ceased.

Table 1. Transport related demonstrations in Bogotá, 1999-2001

Number of protests, strikes and threats of strikes

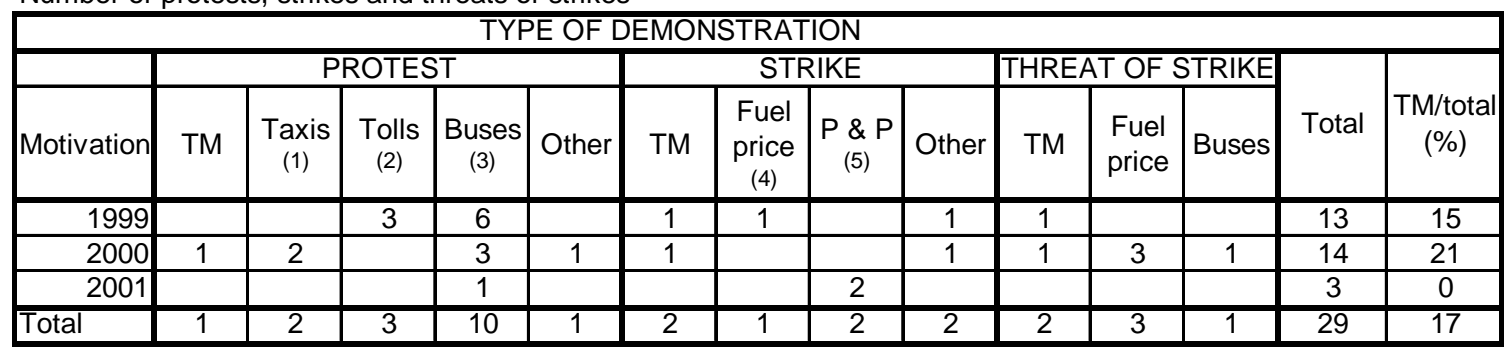

TM: TransMilenio related events.

(1) This refers to protests initiated by taxi drivers and were related to policies and regulations specific to their service.

(2) Transporters covering suburban routes were forced to pay new or higher tolls, leaving or enter the city. They asked for higher fares or lower toll charges.

(3) Demonstrations against bus related regulations, working conditions (such as street insecurity) or other demands, particularly the Replacement Fund to replace old vintage vehicles they wanted the Government to create.

(4) These strikes were promoted because the fuels prices were raised due to oil price rises, particularly frequente during these years (1999-2000).

(5) Pico \& Placa, the prohibition for public transport vehicles to circulate, based on the last digit of the shield number (placas); a measure designed to reduce congestion.

Protest: spontaneous gathering to demonstrate against transport regulation

Strike: organized protest, planned and convoked in advanced

Threat of strike: some strikes were announced to press the authorities in relation to certain issues but they were canceled before they started.

Source: CINEP base on newspaper information, Bogotá.

Another important factor facilitating the transition was the National Government's decision to support a new transportation system for Bogotá. Indeed, the willingness of the central government to partly finance the infrastructure investments associated with it became a critical argument to convince transporters that this was the right time for reform. During the 1990s Colombian presidents supported alternatively either a subway or a bus solution. Consequently, the mayoral candidates for Bogotá and the elected mayor followed suit, praising the system the Nation was willing to support. Any solution 
required substantial financial resources and would have implied high opportunity costs to the Municipal Administration. Thus, choices of the local authorities regarding the best public transport system were partly determined from the outside. In fact, in 1999 only after a new National Government rejected the subway alternative for Bogotá did city authorities reveal their plans for $\mathrm{TM}^{17}$.

Facing a seemingly irreversible regime change, the traditional transporters were practically forced into participating. Also, the municipal government decided that any solution would be pursued in association with the traditional transporting firms of Bogotá. Hence, the actors who could be most negatively affected were not the big affiliating firms but the small bus owners and drivers. They reacted against the proposal and used strikes to block streets as a means of stopping its ratification (see Table 1), but the new coalition between the Municipal Government and the big firms defeated them. Additionally, the municipal government used the allocation of new routes in the non-TM corridors to reward or punish affiliating firms for their willingness to participate in TM through. Hence, the traditional transporters relocated their buses to other, new routes, granted by TM authorities. The choice was then not to abandon the old business in the proportion in which TM replaced them, but just relocation. This produced damaging effects on the other corridors in terms of speed, congestion, pollution, riding time, as it will be illustrated ahead.

The TM system definitely changed the source and distribution of rents from bus public transport in Bogotá. First, for decades setting bus fares above marginal cost basically determined rents. Since bidding for TM is based on a minimum fare offered, and the TM contract determines fare variation, this source of rents is eliminated. This permanently changes the political economy of the sector. Second, on-the-road competition is eliminated because individual firms own buses (not routes), their running instructions are based on service demand, and the remuneration depends on the number of kilometers

\footnotetext{
${ }^{17}$ In 1993 Bogotá undertook an institutional reform in accordance with the 1991 Colombian Constitution. This reform enhanced the powers of the mayor and reduced the influence of the city council. Prior to 1993, the city council greatly influenced public utilities and transportation policies. That reform made it easier to privatize public utilities, in particular the power generation and transmission company whose proceeds improved the city's investment capacity.
} 
and not on the number of passengers. Third, working as a unified firm leads TM to internalize the inefficiency of the previous decentralized, over-invested arrangement. Fourth, in terms of design, TM abides to the crucial conditions of an underground-type system: well-defined and enforceable curbside and road property rights. Allocating property rights via long-term concessions eliminated the Tragedy of the Commons. Fifth, TM eliminates the negative congestion externality on TM corridors.

Some issues present potential vulnerabilities. As Estache and Gomez-Lobo (2004) indicate, the institutional capacity of the planning (national and municipal) authorities for defining the network configuration, quality requirements and service levels is crucial. One of the advantages of the existing private system is its flexibility to modify routes, cover new developing areas of the city, and bring bus routes closer to consumers. These challenges need to be answered satisfactorily now by good planning and regulation. The tendering system requires special care to ensure competition and avoid collusion among potential bidding concessionaires, as it has been argued in the case of Pereira, the second city of Colombia where a TM type is now being implemented. The application of contracts needs also to be monitored. This is particularly true for the revenue collection contract, whose performance is central to the system's profitability.

Recent events have shown other deficiencies as well. In particular, the number of daily passengers is claimed to have increased from 800 to 900 thousand and the number of vehicles on the road remains at the minimum. Passenger jamming became the rule, $a$ particularly severe problem during peak hours. Long lines to purchase access cards were coupled with crowds waiting at the curb to enter the buses. People found it difficult to board the buses. Waiting time, a critical variable in any public transportation system and one of TM's big achievements early on, started to rise. Security deteriorated and theft became common. As a result, people started to complain about the monopoly of $\mathrm{TM}^{18}$.

\footnotetext{
18 "Transmi-Lleno" ("Transmi-full") became slang for TM. On March 10, 2004, after an accident delayed for hours a long queue of TM buses, passengers decided to protest by sitting on the road. Currently overcrowding is worse than in the traditional bus system. On top of this, open fare competition by the still existing alternatives could present a challenge for TM, if traditional bus owners decide to reduce fares.
} 
Additional vulnerabilities relating to financing and political support can be identified. TM depends on fiscal resources from the city and the nation. Political will as well as financial difficulties can prove an obstacle in the future. In this respect, it is interesting to evaluate the importance of personalities versus institutions for the creation and continuation of TM. If it is true that the creation of TM relied on the strong political will and credible threats by a group of transformers, during the last two municipal administrations the system's institutional framework has strengthened. The proof came with the new national and municipal administrations that entered office in August 2002 and 2004, respectively. Some of their advocates criticized aspects of the TM system during the campaign, but once in office they embraced its functioning and defend it.

Lastly, a democratically elected mayor appoints the head of the public company TransMilenio S.A. Thus, TM regulation could be contingent to political decisions. The system needs to strengthen an impersonal and institutionalized regulatory arrangement. Currently, across time one or two individuals may decide the future of the entire system, and only contracts hold their inter-temporal coherence. One of such decision might have involved the scraping process of the first lines of TM. This new hybrid model has vulnerabilities in several instances of the regulation which should be carefully considered and continuously monitored.

\section{Cost-Benefit Analysis: The First Wave of Contracts}

The ultimate goal of TM is to improve the quality of life in Bogotá. Although only 25 percent of the system has been put in place so far, the impact is already indicative of what can be achieved. Travel times for TM passengers dropped and traffic congestion, air pollution, noise levels and frequency of traffic accidents decreased significantly in TM corridors. However, some unexpected negative spillovers have emerged. Traffic congestion and pollution have heightened along corridors not served by TM due to the slow scrapping rate of buses in the traditional public transit system. This section presents a cost-benefit analysis of the first wave of TM contracts ${ }^{19}$.

${ }^{19}$ The first wave of TM contracts covers 25 percent of the system. 


\subsection{The Impact of TM on the Quality of Life in Bogotá}

Soon after TM came into operation, many public transport users switched to this new alternative public transit mode. The year before the introduction of TM, 69 percent of individuals relied in public transportation. In 2001, after TM was available, six percent of individuals switched from traditional public services to the new alternative. This share of the population using TM has expanded constantly and, in 2003, the new system was the transportation alternative for 13 percent of the population ${ }^{20}$. It is interesting to note however that TM has not increased the overall attractiveness of public transit since the share of the population using cars remained constant after the adoption of TM.

Although demand for public transport stems mainly from the lower-income households, TM users are concentrated in the fourth and fifth income quintiles. Figure 5.a depicts transport mode by income quintile. Demand for buses is concentrated on the first, second and third quintile whereas use of private vehicles is restricted to the fourth and fifth income quintile. Demand for TM by income quintile is illustrated in graph 5.b. The highest income quintiles are the main users of TM.


Source: authors calculations based on ECV (2003)

The impact of TM on travel times and average speed varies widely across TM users, private vehicles and the traditional public transport system users. Two years after TM came into operation, the average trip time in Bogotá decreased to 35 minutes from 44 minutes in 2001. The average speed of cars increased to 32.18 kilometers per hour from 27.03

\footnotetext{
${ }^{20}$ The first phase of TM, that is 25 percent of the network, covers 13 percent of the public transport demand in Bogotá.
} 
kilometers per hour in 2000 (Secretary of Transit and Transportation, 2003). Table 2 shows that the percentage of individuals who spent more than an hour traveling from home to work descended to 17 percent from 23 percent while the frequency of travel trips below one hour rose during 2003.

Table 2. Time spent traveling from home to work, Percentage of individuals

\begin{tabular}{lccc}
\hline & $\mathbf{2 0 0 1}$ & $\mathbf{2 0 0 2}$ & $\mathbf{2 0 0 3}$ \\
\hline Less than one hour & $74 \%$ & $68 \%$ & $74 \%$ \\
Between one and two hour: & $23 \%$ & $29 \%$ & $17 \%$ \\
More than two hours & $4 \%$ & $2 \%$ & $5 \%$ \\
\hline \multicolumn{2}{c}{ Source: Authors calculations based on Napoleon Franco }
\end{tabular}

However, the benefits of reductions in travel times accrued mainly to TM users. The average speed of other public transport actually dropped, which caused travel times to increase by ten percent (Lleras, 2003). Slow scrapping of buses from the traditional system may be causing the uneven distribution of benefits. These buses have relocated to corridors not served by TM, worsening congestion (Lleras, 2003).

The impact of TM for public transports users, mainly upon travel times, is studied by Lleras (2003). A revealed preference survey was applied in 2002 to 2095 public transport riders that could choose between TM and the traditional system as transport modes. Respondents were interviewed in the street near areas where routes from the two systems run. The survey elicited information about the transport mode selected, the expected attributes of the trip, and some socio-economic characteristics. The data was used to estimate random utility models, which provide the coefficients to calculate the value of time for transport users of both systems in the different stages of the process (e.g. walk in and walk out time).

Declines in travel times were not uniform across TM users. For passengers starting the trip in the vicinity of the main corridors, TM users travel 12 minutes less per trip compared to passengers of the traditional system. On the other hand, passengers requiring one or several transfers did not experience drops in travel times. In fact, total travel time is two minutes shorter in the traditional system due to waiting time required for the feeder routes (Lleras, 2003). 
It is important to note however that waiting-in and waiting-out time increased for all TM users because these times are extremely low for the traditional bus system ${ }^{21}$. While TM users have to buy tickets, wait in line, exit the station and walk to the final destination, users of the traditional system pay the bus driver, enter the bus at any location and stop the bus at the point nearest to their destination. Improvements in travel times arise, therefore, from in-vehicle travel time.

Estimations of the value of time for TM passengers vis-à-vis users of the traditional system show unambiguous improvements in traveling conditions for the former. Overall, people are willing to pay more for savings in travel time than in the traditional system, indicating that TM is a less "painful" experience. For example, the value of waiting time for the traditional system is US\$3.08 per hour while in TM it is US\$1.14 per hour (Lleras, 2003).

The figures analyzed above indicate that the first phase of TM enhanced travel conditions for a population group. While improvements should not be entirely attributed to the new mass transit system ${ }^{22}$, the evidence is highly suggestive. Nevertheless, benefits from the new system are not distributed widely across the entire population; gains were perceived largely by TM users, in particular downtown dwellers.

The quality of services also improved. Traffic accidents decreased dramatically in TM corridors. Figure 6 depicts the incidence of traffic collisions, pedestrian accidents, injuries and fatalities in TM corridors before and after the system came into operation. After two years, traffic collisions and pedestrian accidents decreased by 94 percent, passengers injured by 76 percent and fatalities by 94 percent. This is by all accounts an impressive performance.

\footnotetext{
${ }^{21}$ For example, Llerras (2003) estimates that waiting-in and waiting-out time increased 2.95 and 5.16 minutes for TM users vis-à-vis users of the traditional public transport system.

22 Bogotá's authorities implemented several programs to transform traffic conditions: mobilization restrictions during traffic peaks, investments in road infrastructure and higher traffic fines.
} 


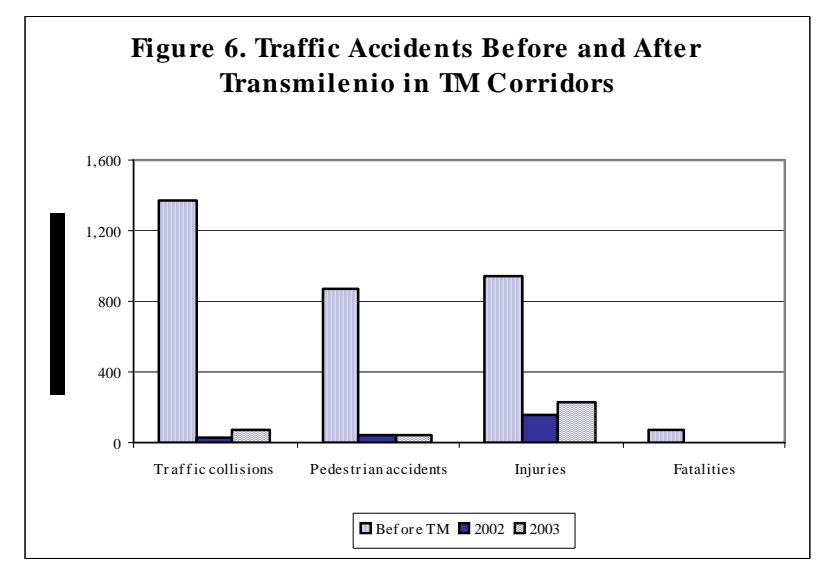

Source: TM S.A.

Lastly, air pollution, a major concern in Bogotá, exhibited a declining trend in TM corridors. Currently, half of the districts in the city exceed the Particulate Matter (PM-10) and Ozone pollution limits. Studies indicate automobiles, the most significant emission source in Bogotá, contribute 70 percent of air pollution (Cavallazi, 1996). Reductions in traffic congestion increased the speed of other vehicles, curbing emissions in TM corridors. In addition, TM appears to have improved air quality by transporting more passengers in less time and with better vehicles.

This superior performance of TM vehicles, in contrast to traditional public buses, contributes to controlling mobile source emissions. TM buses transport 1,596 passengers daily, five times the number of traditional public buses, and the average speed is 17 to 44 percent greater than the average speed in public transportation. Moreover, the average age of public buses is 15 years and maintenance, an important mechanism to reduce emissions from mobile sources, is rarely performed. On the other hand, TM buses have catalytic converters, emissions are below the limits required by the Euro II norm, some vehicles use natural gas and noise levels are less than 90 decibels (Ibáñez and Uribe, 2003).

As stated, air pollution levels in TM corridors have decreased significantly. During the period 2000-2002, while the citywide average of Particulate Matter emissions grew by 23 percent, it fell by 8 and 11 percent in the two TM corridors shown in Figure 7 . However, the declining air pollution trend may not necessarily be the result of TM. During the last decade, 
the environmental authorities of Bogotá have adopted a group of measures ${ }^{23}$ to control air pollution that may have achieved effectively their objective.



Source: Authors calculations based on $\mathrm{RMCAB}^{24}$

Méndez (2004) analyzes the impact of several pollution programs implemented in Bogotá. The evolution of particulate matter and ozone in monitoring stations located near TM corridors and far from industrial areas was evaluated between the years 1997 to 2002 . Categorical variables to denote the implementation of three policy interventions - the introduction of TM, mobilization restrictions and mandatory inspection and maintenance were defined. Time series regressions to predict the trend of particulate matter and ozone levels and controlling for these policy interventions are estimated ${ }^{25}$.

Results reveal that TM is the most effective program for curbing pollution, in stark contrast to programs purposively designed to control emissions. While mandatory inspection and maintenance and restrictions in car mobilization reduce ozone levels by 13.6 and 21 percent respectively, the first phase of TM produced a 28.8 percent decline in ozone levels. Similar estimations for particulate matter indicate TM abated pollution levels by 9.2 percent.

\footnotetext{
${ }^{23}$ Measures include the use of catalytic converters for new cars, mandatory inspection and maintenance and mobilization restrictions.

${ }_{24}$ RMCAB stands for the network of air pollution monitoring stations in Bogotá. Thirteen monitoring stations, measuring hourly emissions for a group of pollutants, are located along Bogotá.

${ }^{25}$ To evaluate the impact of TM on emissions of Particulate Matter, a difference-in-differences analysis was carried out. The analysis seeks to compare readings from a monitoring station located near a TM corridor to readings at a baseline monitoring station. The baseline monitoring station should have two characteristics: (i) similar particulate matter readings to the TM monitoring station before entry into operation of the system; and (ii) location near a non-TM corridor without negative spillovers from relocation of buses. Unfortunately, it is practically impossible to find a monitoring station that satisfies both characteristics simultaneously.
} 
Given that the slow scrapping rate of buses from the traditional system triggered the relocation of buses to non-TM corridors, in these areas the city experienced higher air pollution levels. The negative pollution spillovers of TM were evaluated using a differencein-difference approach. Two monitoring stations were selected based on the following criteria. First, particulate matter readings should be similar in both monitoring stations before the entry into operation of TM. Second, monitoring stations should not be located near industrial areas. Third, one monitoring station should be facing negative spillovers from relocation of buses and the other monitoring station should not be facing negative spillovers. The evolution of particulate matters in both monitoring stations is illustrated in Figure 8. After full entry into operation of TM in June $2001^{26}$, particulate matter readings soared in the monitoring stations with negative spillovers while it remained constant in the monitoring station without the negative spillovers. The difference-in-difference calculations indicate that relocation of buses caused particulate matter emissions to increase by 10.5 percent, more than offsetting the reductions in $\mathrm{PM}-10$ readings in TM corridors.



Air pollution can seriously cause damages to health; particulate matter and ozone levels appear to increase the incidence of acute respiratory illnesses in Bogotá (Lozano, 2003). By estimating a concentration response function that link daily respiratory hospital admissions during 1998, the study finds a strong link between incidence of respiratory health admissions and particulate matter levels. In fact, a 25 percent increase in particulate

\footnotetext{
${ }^{26}$ TM started partial operations in January 2001 and in June 2001 the full system with the three trunk corridors was put in place.
} 
matter causes 21.8 percent more respiratory health admissions, but decreasing particulate matter emissions by 25 percent signifies a 17 percent reduction in health respiratory admissions.

The impact of the first phase of TM reveals ambiguous results. On the one hand, travel times for TM users fell, safety improved, congestion dropped and air quality increased; yet these benefits are restricted to TM corridors and did not spread citywide. On the other hand, relocation of buses, as a result of slow scrapping rates, deteriorated congestion in non-TM corridors; causing a deterioration of traveling conditions for passengers of the traditional system, and of pollution levels. It is important to note that once the full system comes into operation the negative spillovers should decrease significantly or disappear. In 2015, the full TM network will be completed and will cover 80 percent of public transport demand in Bogotá. Notwithstanding, negative spillovers of TM should be taken into account when implementing the next phases.

\subsection{Cost-Benefit Analysis}

Understanding the welfare gains and losses from the introduction of TM is crucial to evaluate whether investments in this new scheme derived in net benefits for the population, and to identify future adjustments to the system. Welfare changes can be approximated measuring variations in the consumer and producer surplus caused by the adoption of TM. The previous information along with data on investments, costs and revenues of the system's operation was utilized to conduct a cost-benefit analysis. Only the first phase of TM - 25 percent of the system - was evaluated. Ideally, the analysis should estimate the consumer and producer surplus before and after TM, and then proceed to calculate the changes in both surpluses; yet restrictions on the data only made it possible to calculate changes in both surpluses as a result of the adoption of the system. A detailed description of the assumptions and methodology used to perform the analysis is included in Appendix II. Table 3 presents a summary of results ${ }^{27}$.

The CBA analysis incorporates revenues and costs from the operation of TM as well as initial investment. Operational information comprises revenues from fare collections,

${ }^{27}$ Detailed calculations of the cost-benefits are available upon request. 
operational costs for concessionaires, fare collection expenses, administrative expenditures of TransMilenio S.A and management costs for the fiduciary. Infrastructure investments and maintenance costs of corridors are also incorporated.

The foregone revenues of firms operating previously in TM corridors were also calculated. Before TM came into operation, near 6080 buses operated in those corridors; approximately 1410 were scrapped and the remaining 4670 were relocated to unserved TM corridors. Foregone revenues were estimated for the former whereas revenues for the latter are incorporated because the operation of these buses did not stop.

Welfare losses and gains from variations in travel times for users of TM and the traditional system were estimated. All stages involved when traveling from one destination to another were considered: waiting time, in-vehicle travel time as well as walking-in and walking-out time. Lleras (2003) calculated the value of time for each stage. Public transport demand was divided in two groups: (i) users that require one or more transfers; and (ii) users that travel directly to their destination. Values were calculated for both segments.

Benefits and costs associated with changes in particulate matter levels were estimated. Figures from emissions reductions in TM corridors were extracted from Méndez (2004). Emission increases from negative spillovers were calculated using a difference-indifferences approach. The impact of particulate matter pollution on incidence of acute respiratory illnesses was calculated based on a concentration-response function estimated by Lozano (2003) for Bogotá. Changes in the incidence of Acute Respiratory Illness as a consequence of TM were valued using willingness to pay for reductions in respiratory health admissions reported by Lozano (2003).

Lastly, gains from drops in traffic fatalities in TM corridors are calculated. The risk of death before and after TM was estimated based on the number of passengers and the number of deaths. The Value of a Statistical Life (VSL) for Chile reported in Bowland and Beghin (1998) was adjusted for Colombia using the GNP per capita for both countries.

Many benefits accruing from TM were not incorporated in the analysis due to data restrictions. First, higher property values for houses located on TM corridors are not considered. Second, gains from traffic collisions and injuries reported in Figure 6. were not 
included since no data is available to approximate welfare gains from these events. Third, petty thefts and general insecurity fell significantly in TM corridors but data to calculate welfare benefits from increased security is not available.

The net present value of the cost-benefit analysis is presented for different discount rates in 3. Results reveal net benefits from the first phase of TM are negative and equal to US $\$ 64$ million for a discount rate of nine percent. High infrastructure investments not recovered by fares and increases in travel times for users of the traditional system, as a consequence of relocation of buses, drive these results. Infrastructure investments and costs to traditional system users account for 66 and 25 percent of negative net benefits respectively. Pollution in non-TM corridors also reduces benefits, but contributions are not significant and are partially offset by drops in pollution in TM corridors. Benefits stemming from less in-vehicle travel time for TM users, operational revenues and reductions in mortality, although significant, are not sufficient to cover these costs.

Negative spillovers are the results of three features of the current mass transit system of Bogotá. First, only 25 percent of the TM network has been constructed so far. Because the TM network is only partially operating, the benefits arising from the economics of coordination and density are not being exploited fully. Second, scrapping rates required on the first phase of TM contracts were insufficient. As a result, buses previously operating in TM corridors were not scrapped and relocated to unserved corridors heightening congestion. Lastly, high fares and imperfect controls on the entry of new buses of the traditional public system promoted the entry of new buses and slowed the exit of old ones. Fares are still excessively high and are an incentive for entry of new buses. In addition, controls for the entry of new buses are difficult to enforce, allowing for the operation of "pirate buses" city wide. 
Table 3. Cost-Benefit Analysis with Infrastructure Costs Millions of dollars 2002

\begin{tabular}{|c|c|c|c|}
\hline \multirow{2}{*}{ Item } & \multicolumn{3}{|c|}{ Discount rate } \\
\hline & $7 \%$ & $9 \%$ & $12 \%$ \\
\hline Foregone Revenues - Traditional System & $-15,65$ & $-11,73$ & $-9,12$ \\
\hline Foregone Operational Costs - Traditional System & 12,27 & 9,20 & 7,15 \\
\hline Revenues -Relocated Buses & 12,02 & 9,01 & 7,00 \\
\hline Operational Costs - Relocated Buses & $-9,42$ & $-7,06$ & $-5,49$ \\
\hline Revenues - TransMilenio & 6,86 & 5,05 & 3,87 \\
\hline Operational Costs - TransMilenio & $-6,01$ & $-4,41$ & $-3,38$ \\
\hline Infrastructure Costs & $-55,02$ & $-42,61$ & $-33,86$ \\
\hline Maintenance Costs & $-1,84$ & $-1,38$ & $-1,07$ \\
\hline Costs due to increase in Waiting Time for TM - Non transfer & $-0,61$ & $-0,45$ & $-0,34$ \\
\hline Costs due to increase in Waiting Time for TM - Transfer & $-1,69$ & $-1,24$ & $-0,95$ \\
\hline Costs due to increase in Walking In and Out Time for TM - Non transfer & $-2,77$ & $-2,03$ & $-1,56$ \\
\hline Costs due to increase in Walking In and Out Time for TM - Transfer & $-3,03$ & $-2,23$ & $-1,71$ \\
\hline Benefits associated with reductions in Travel Time for TM - Non transfer & 6,22 & 4,57 & 3,50 \\
\hline Benefits associated with reductions in Travel Time for TM - Transfer & 5,85 & 4,30 & 3,30 \\
\hline Costs due to increase in Travel Time for Traditional System users - Non transfer & $-10,63$ & $-7,97$ & $-6,19$ \\
\hline Travel time costs for Traditional System users - Transfer & $-21,70$ & $-16,27$ & $-12,64$ \\
\hline Costs asocciated with a $10.5 \%$ increase in PM10 in traditional corridors & $-0,36$ & $-0,27$ & $-0,21$ \\
\hline Benefits associated with a 9.1\% reduction in PM10 in TM corridors & 0,28 & 0,21 & 0,16 \\
\hline Benefits due to reductions in mortality & 0,83 & 0,62 & 0,49 \\
\hline Net Present Value & $-84,37$ & $-64,68$ & $-51,04$ \\
\hline
\end{tabular}

Source: Authors calculations.

Two important caveats about the results should be mentioned. Some benefits such as increased property values, fewer traffic accidents and better security in TM corridors are not incorporated into the analysis due to data restrictions, and would certainly change the results. TM is a network and only 25 percent of it has been put in place. Because TM will serve the vast majority of the road network, negative spillovers from relocation of buses should disappear gradually once the network is complete. In fact, the second wave of contracts defined more stringent requirements for scrapping rates.

Notwithstanding, the analysis sheds some light on drawbacks of the TM system that can be adjusted for the next phases. First, the design of the system should take into account negative spillovers to the traditional public transport system in order to minimize them. Both systems - TM and the traditional system - should not operate separately but jointly as an integrated mass transit system. Lastly, prevailing incentives such as high fares that spur entry of new buses, despite the fact that many buses travel empty, should be eliminated (Castro et al, 2001).

The National and Local Government provided the bulk of infrastructure investment. Street pavement, most of which would have been done anyhow, and is the responsibility of the city authorities, constitutes a significant share of this investment. Moreover, the intervention on TM corridors includes a full renovation of two lanes for private cars and the curbside. 
Therefore, benefits from this investment not only accrue to TM providers and users, but to others groups of the population. In addition, imposing on TM the obligation of recovering the infrastructure investments or its maintenance costs would have rendered TM unfeasible because profitability would have been negative, eliminating the participation of the private sector. The National and Local authorities viewed the public provision of infrastructure as sunk costs and subsidies to the population to promote a more efficient public transit system. Based on those arguments, Table 4 presents the CBA analyses without public investment.

Table 4. Cost Benefit Analysis without Infrastructure Costs Millions of dollars of 2002

\begin{tabular}{|c|c|c|c|}
\hline \multirow{2}{*}{ Item } & \multirow[b]{2}{*}{$7 \%$} & \multirow[b]{2}{*}{$9 \%$} & \multirow[b]{2}{*}{$12 \%$} \\
\hline & & & \\
\hline Forgone Revenues - Traditional System & -15.65 & -11.73 & -9.12 \\
\hline Foregone Operational Costs - Traditional System & 11.65 & 8.73 & 6.79 \\
\hline Revenues - Relocated Buses & 12.02 & 9.01 & 7.00 \\
\hline Operational Costs - Relocated Buses & -8.95 & -6.71 & -5.21 \\
\hline Revenues - TransMilenio & 6.86 & 5.05 & 3.87 \\
\hline Operational Costs - TransMilenio & -6.01 & -4.41 & -3.38 \\
\hline Maintenance Costs & -1.84 & -1.38 & -1.07 \\
\hline Costs due to increase in Waiting Time for TM - Non transfer & -0.61 & -0.45 & -0.34 \\
\hline Costs due to increase in Waiting Time for TM - Transfer & -1.69 & -1.24 & -0.95 \\
\hline Costs due to increase in Walking In and Out Time for TM - Non transfer & -2.77 & -2.03 & -1.56 \\
\hline Costs due to increase in Walking In and Out Time for TM - Transfer & -3.03 & -2.23 & -1.71 \\
\hline Benefits associated with reductions in Travel Time for TM - Non Transfer & 6.22 & 4.57 & 3.50 \\
\hline Benefits associates with reductions in Travel Time for TM - Transfer & 5.85 & 4.30 & 3.30 \\
\hline Costs due to increase in Travel Time for Traditional System users - Non Transfer & -10.63 & -7.97 & -6.19 \\
\hline Travel time costs for Traditional System users - Transfer & -21.70 & -16.27 & -12.64 \\
\hline Costs asocciated with a $10.5 \%$ increase in PM10 in traditional corridors & -0.36 & -0.27 & -0.21 \\
\hline Benefits associated with a 9.1\% reduction in PM10 in TM corridors & 0.28 & 0.21 & 0.16 \\
\hline Benefits due to reductions in mortality & 0.83 & 0.62 & 0.49 \\
\hline Net Present Value & -84.51 & -64.78 & -51.12 \\
\hline
\end{tabular}

Source: Authors calculations.

Even without public investment, results for the CBA analysis continue to be negative. In this case, outcomes are mainly caused by the negative spillovers imposed by TM upon passengers of the traditional public transport system. Currently, TM covers 13 percent of the public transport demand whereas the public transport system covers 87 percent. TM indeed improved the traveling conditions of its users, but worsened the conditions of a high proportion of the population: users of the traditional public transport system. This is not implying TM is not a good alternative. On the contrary, TM should be expanded rapidly to improve traveling conditions of other public transport users, and to reduce the negative spillovers. 


\section{Conclusions}

TransMilenio has become a cornerstone in the history of urban public transport in Colombia. Nowadays at least five Colombian cities above 500 thousand people are applying for central government resources in order to replicate the system implemented by Bogotá and other cities in Latin America are planning to follow suit. In its origin, TM itself mimicked the experiences of Curitiba and Quito, but it introduced some novelties that have become its trademark. The new transit system is a hybrid model that combines public planning of the network structure, route tendering conditions, regulation and supervision, as well as private operation of the separated functions of revenue collection and transport service. Among them, the financial fiduciary management, the separation between the private providers which simultaneously administers the firm TransMilenio S.A.; the flexible contracts for bus operation; the separation between feeder buses and regular buses concessions; the payment per kilometer instead of per passenger; the definition of property rights for the road and the curbside; and the choice of the left, faster lanes for it, are the most salient. However, as always, the true test of the pudding is in the tasting, and we can say that in many respects TM has been a success worth being copied itself in other Latin American and Asian cities.

This aggressive initiative had been previously analyzed from different points of view, but this paper is the first attempt to conduct a full economic account of its origin, design, political economy and a cost-benefit analysis. Surprisingly, the cost-benefit analysis for the first phase is negative. The new organization had a sizeable impact on TM users' by improving traveling conditions significantly. In addition, congestion, pollution and traffic accidents plummeted in TM corridors. However, the type of transition adopted for the remaining transport corridors not covered by TM caused unforeseen negative spillovers, as a consequence of slow scrapping rates and bus and routes relocation. Consequently, although the CBA for the first phase of the corridors covered by TM is positive, once these additional measures are taken into consideration, the net effect is negative due primarily to increases in travel time for passengers using the traditional transport system. In order to minimize the negative spillovers during the full implementation of $\mathrm{TM}$, expected to last until 
2015, integration of the traditional and new systems should be carried on, and strict regulation of the traditional public transport system should be crafted. 


\section{References}

Bowland, Brad and Beghin, John (1998). Robust Estimates of Value of a Statistical Life for Developing Economies: An Application to Pollution and Mortality in Santiago. Staff General Research Papers No. 4046. Department of Economics, Iowa State University.

Cavallazi, Marcelo. (1996). "Contaminación atmosférica en Bogotá", Revista Cámara de Comercio No. 97. Bogotá, Colombia.

Castro, Raúl, Leonardo García, Hernán Jiménez, Orlando Garcés and Andrés Navarré (2001). Cálculo de la tarifa óptima para el Sistema de Transporte Masivo Transmilenio. Department of Economics. Universidad de los Andes. Final Report presented to Transmilenio S.A.

Engel, Eduardo M.R., Ronald D. Fischer and Alexander Galetovic (2001). "Least-Present Value-of-Revenue Auctions and Highway Franchising", Journal of Political Economy,109 (5): 993-1020.

Evans, Andrew (1987). "A Theoretical Comparison of Competition with Other Economic Regimes for Bus Services", Journal of Transport Economics and Policy, 21:7-36.

Estache Antonio and Gómez-Lobo Andrés (2004). The Limits to Competition in Urban Bus Services in Developing Countries. World Bank Policy Research Working Paper 3207.

Hillón, Luis Carlos (2002). Ineficiencias económicas en la provisión privada de vehículos para el Transporte Público Urbano en Colombia: 1970-1999. Masters Thesis. Department of Economics. Universidad de los Andes, Bogotá, Colombia.

Ibáñez, Ana Maria and Uribe, Eduardo (2003). Medio ambiente y desarrollo económico: Priorización de la inversión ambiental con criterios económicos. Documento CEDE 2003-33. Universidad de los Andes, Bogotá, Colombia.

JICA (1998) The Feasibility Study on the Project of Highway and Bus Lane of Santa Fe de Bogotá in the Republic of Colombia. Progress Report.

Klein Daniel B, Binyam, Reja and Moore, Adrian (1997). Curb Rights: A Foundation for Free Enterprise in Urban Transit. The Brookings Institution. Washington DC. United States.

Lleras, Germán (2003). Bus Rapid Transit: Impacts on Travel Behavior in Bogotá. Masters Thesis. Department of Urban Studies and Planning. MIT. Boston, Massachusetts.

Lozano, Nancy (2003). Air Pollution in Bogotá, Colombia: A Concentration-Response Approach. Masters Thesis. Department of Agriculture and Resource Economics. University of Maryland, College Park, Maryland.

Méndez, Mildred (2004). Análisis de intervención: efectividad de las políticas para reducción de la contaminación por fuentes móviles en Bogotá. Masters Thesis. Department of Economics. Universidad de los Andes, Bogotá, Colombia. 
Urrutia, Miguel (1981). Buses y Busetas, Una Evaluación del Transporte Urbano en Bogotá, Fedesarrollo. Bogotá, Colombia. 


\section{Appendix I: Econometric Estimates for Rents}

In order to calculate the economic rents for affiliating firms and bus drivers, the demand per vehicle and the income per passenger were estimated using time series regressions. Two approaches were utilized. The first approach estimates an OLS regression that corrects for autocorrelation. The second approach estimates an ARMAX model.

The observed demand per vehicle is estimated with a distributed lagged model where a lagged variable for the number of passengers is included as an explanatory variable

$$
q_{t}=\beta_{0}+\beta_{1} q_{t-1}+\beta_{2} v_{t}^{2}+\varepsilon_{t}+\delta \varepsilon_{t-1}
$$

where $q_{t}$ is the daily number of passengers per vehicle, $q_{t-1}$ is the lagged daily number of passengers and $v_{t}$ represents the number of buses. Several models were estimated. The model that best approximates the functional form is presented table I.1.



The ARMAX model provides the best estimation and autocorrelation is eliminated. The signs of the coefficients are as expected. $\beta_{0}$ is equivalent to autonomous demand, $\beta_{1}$ incorporates the influence of prior periods and $\beta_{2}$ the influence of size of the total fleet, which is negative in all the estimates.

To estimate income per passenger the production function curve for a congestion good is estimated using a polynomial regression model.

$$
Y_{t}=\alpha_{0}+\alpha_{1} V+\alpha_{2} v^{2}+\alpha_{3} v^{3}+\varepsilon_{t}+\delta \varepsilon_{t-1}
$$

where $Y$ represents the income per passenger, which is a variable that approximates the fare. To correct for autocorrelation, ARMAX and AR1 models were estimated. The results are presented in Table I.2. 
Table I.2. Econometric estimates of income per passenger

\begin{tabular}{cccc}
\hline & OLS & AR 1 & ARMAX \\
\hline$\alpha_{0}$ & 52.8123 & 21.4539 & 33.5797 \\
$\alpha_{1}$ & $-0.1212 \times 10^{-1}$ & $-0.5918 \times 10^{-3}$ & $-0.7134 \times 10^{-2}$ \\
$\alpha_{2}$ & $0.1062 \times 10^{-5}$ & $0.1053 \times 10^{-6}$ & $-0.6694 \times 10^{-6}$ \\
$\alpha_{3}$ & $-0.2484 \times 10^{-10}$ & $-0.2776 \times 10^{-11}$ & $-0.1538 \times 10^{-10}$ \\
$\delta$ & & 0.9674 & 0.8316 \\
SS & 284.49 & 139.77 & 137.78 \\
$\mathrm{E}\left(\varepsilon_{\mathrm{t}}\right)$ & $0.7466^{*}$ & $\neq 0$ & $=0$ \\
\hline
\end{tabular}

Source: Authors' calculation

SS: Sum of the square of the errors

$E\left(\varepsilon_{t}\right)=0$, Implies that autocorrelation does not persist

*Value of Durbin Watson

** Significant at $2 \%$

To calculate rents, gains and costs to each vehicle should be calculated. Gains are determined by the number of vehicles in circulation for which a production function of the public transport sector is defined. Costs per vehicle are determined and include fuel expenses, spare parts replacement, maintenance, depreciation, insurance costs, taxes and purchase value of the vehicle ${ }^{28}$. The average cost per vehicle was calculated for each year. Rents for the affiliating firms are estimated by adding up the benefits for the buses they owned, revenues from routes allocations and the operational costs.

Contracts between the affiliating firm and bus owners are simulated by maximizing benefits from affiliating firms subject to positive benefits for the bus owners. The optimal number of vehicles per affiliating firm, the affiliation fee as well as rents for the affiliating firm and bus owners are obtained.

${ }^{28}$ The prevailing interest rate for each year was used. 


\section{Appendix II: Methodology of the Cost-Benefit Analysis}

1. The analysis was performed for the length of the first wave of the contract: 20002015.

2. All values are in US\$ millions of 2002 .

3. Revenues for Transmilenio: Number of TM users multiplied by the technical fare. For 2001, 2002 and 2003 observed values for number of passengers reported by TransMilenio S.A. were used. For 2004 onwards, the revenues were calculated assuming that the number of passengers increased with the population growth rate projected by DANE.

4. Revenues for Traditional System Buses:

a. The number of passengers on Caracas and Avenida 80 corridors before TransMilenio was taken from the National Department of Statistics (DANE) for 1996 and adjusted for 2001 using population growth rates for Bogotá.

b. Revenues and costs per passenger for the different types of buses that operated in these trunk corridors before TransMilenio were taken from Castro et al (2001)

c. The estimation of the number of buses that operated in these trunk corridors was based upon the number of routes in these corridors and the average number of buses per route. This information was provided by Express del Futuro, one of the concessionaires of TM. Approximately 6080 buses operated in these corridors.

d. Transmilenio S.A. reported that for every TransMilenio bus that entered the system, three traditional system buses were scrapped. Near 470 TransMilenio buses came in operation, so consequently, 1410 were effectively scrapped; this corresponds to $23.2 \%$ of the buses that operated in these corridors. The remaining $76.8 \%$ of the traditional system buses is assumed to have relocated to other corridors.

e. The foregone revenues for the traditional system buses was calculated as the number of passengers multiplied by the revenue per passenger for buses in Caracas and Avenida 80 corridors.

f. Gains due to foregone operational costs of traditional buses previously operating in TM corridors was calculated as the number of passengers multiplied by the operational cost per passenger for buses in Caracas and Avenida 80 corridors.

g. Operational revenues for buses of the traditional system that relocated to unserved TM corridors were calculated as the revenues for buses of the traditional system multiplied by the percentage of buses that relocated to other corridors (76.81\%).

h. Operational costs for buses of the traditional system that relocated to unserved TM corridors were calculated as the operational costs of traditional buses multiplied by the percentage of buses that relocated to other corridors (76.81\%).

5. Population growth rates: For 2004 and 2005, rates projected by DANE were used. For 2006 onwards, the average population growth for 2001-2005 was used.

\section{Operational Costs:}


a. Feeder lines cost: Number of passengers in the feeder lines multiplied by the feeder rate per passenger. Observed values reported by TransMilenio S.A. were used for 2001, 2002 and 2003. For 2004 onwards, the number of passengers increases by the population growth rate.

b. Trunk corridor cost: Number of km. multiplied by bus fare per km. Observed values reported by TransMilenio S.A. were used for 2001, 2002 and 2003.

c. Fare collection costs: Calculated as a rate per passenger multiplied by the number of passengers. Observed values reported by TransMilenio S.A. were used for 2001, 2002 and 2003. For 2004 onwards, number of passengers grew with population growth rate.

d. Operational costs for TransMilenio S.A: three percent over the technical fare multiplied by the number of passengers. Observed values reported by TransMilenio S.A. were used for 2001, 2002 and 2003. For 2004 onwards, the number of passengers grew with population growth rate.

e. Fiduciary contract cost: $0.0387 \%$ of total revenues

7. Infrastructure costs: Values reported by Lleras (2003) for the First Phase of TM. Costs include: trunk corridors, bus stations, bus terminals, access to stations, bus depots, operations control center, buses and others.

8. Maintenance Costs: Total maintenance costs reported by IDU-TM.

9. Time Costs:

a. Waiting Time Costs: The value of time was extracted from Lleras (2003). Increases in waiting time were calculated as the difference between TM and traditional system users waiting time. This figure was multiplied by the value of waiting time for TM users and the number of TM users.

b. Walking In and Out Time Costs: The value of time was extracted from Lleras (2003). Increases in walking in and out times were calculated as the difference between TM and traditional system users walking in and out times. This figure was multiplied by the value of walking time for TM users times the number of TM users.

c. In vehicle travel time: The value of time was extracted from Lleras (2003). Drops in in-vehicle travel time were calculated as the difference between TM and traditional system users in-vehicle travel time. This figure was multiplied by the value of travel time for traditional system users and the number of traditional system users.

d. Travel time for users of the traditional system: The value of time was extracted from Lleras (2003). Increases in travel time for users of the traditional system amount to ten percent according to Lleras (2003). This increase was multiplied by the value of travel time for traditional system users and the number of traditional system users.

e. All times were assumed to remain constant over the period of analysis.

f. For TM times, all times were calculated for two segments of the population. Segment one includes users whose trips originated in the vicinity of the Trunk Corridors and therefore did not need to make transfers, i.e. those who do not use feeder lines. Following Lleras (2003) 55 percent of the population belongs to segment one. The remaining $45 \%$ belong to Segment 2, which includes those who start their trips in areas served by feeder lines and, therefore, have to engage in one or several transfers. 
g. For traditional system times, all times were calculated for two segments of the population. Segment one includes those who only take one bus to their destination; $55 \%$ of the population belongs to segment one. The remaining $45 \%$ belongs to segmented two, which includes those who take two or more buses in order to arrive to their destinations.

\section{Air pollution}

a. Reductions in PM-10 associated with TM operations in trunk corridors were based on Mendez (2004).

b. Emissions reductions in TM corridors are supposed to benefit 20 percent of the population.

c. Difference-in-differences analysis was conducted to find the increases in PM10 associated with traffic spillovers to non-TM corridors.

d. Emissions increases in TM corridors are supposed to affect 20 percent of the population.

\section{Reductions in mortality:}

a. VSL estimates for Chile (Bowland and Beghin, 1998) were adjusted for Colombia using the GNP per capita of both countries.

b. The risk of death for public transport users before TM was calculated as the number of deaths divided by the number of users.

c. The risk of death for public transport users after TM was calculated as the number of deaths divided by the number of users.

12. Net present value: Social discount rates of $7 \%, 9.33 \%$ and $12 \%$ were used to calculate TM's net present value. 